\title{
GUATEMALA 2008: LA DEMOCRACIA EN MEDIO DE UN ESCENARIO COMPLEJO
}

\author{
Guatemala 2008: Democracy in the Midst of a Complex Scenario
}

\author{
RENZO LAUTARO ROSAL \\ Instituto Centroamericano de Estudios Políticos (INCEP) \\ HUGO ANTONIO SOLARES \\ Instituto Centroamericano de Estudios Políticos (INCEP)
}

\begin{abstract}
RESUMEN
A lo largo del 2008 la democracia guatemalteca logró algunos avances significativos, pero también debió encarar dificultades que obligan a redoblar esfuerzos para el nuevo año. En primer lugar, en el país dio inicio un nuevo gobierno, cuya juramentación consolida el proceso democrático en curso. La orientación socialdemócrata de la nueva administración ha generado expectativas de un mayor apoyo a las políticas sociales en favor de la población más pobre, así como una mayor apertura al diálogo con la sociedad civil organizada. A pesar de estos signos positivos, el país se vio afectado por la crisis económica mundial, cuyo empeoramiento se espera en 2009, lo que puede contribuir a complicar aún más las condiciones de pobreza en que viven amplios sectores de la población. Esta situación se produce en medio de niveles inusitados de criminalidad y violencia, generadas por pandillas juveniles y, especialmente, por las redes del crimen organizado encabezadas por el narcotráfico. La situación no llama al optimismo, pero tampoco es conveniente asumir una actitud de derrota, dados los potenciales que tiene el país para recuperarse y seguir avanzando.
\end{abstract}

Palabras clave: Democracia, criminalidad, pobreza, estabilidad macroeconómica, partidos políticos.

\begin{abstract}
Through the year 2008, Guatemalan democracy achieved some significant advances, but at the same time the Nation was required to face many difficulties that obligate to double efforts. First, the country started a new Government that consolidated the democratic process. The Social-Democrat ideological orientation of the new administration has produced expectations about a bigger support to social policies favorable to the poorest people, and about a greater opening to dialogue with civil society. Despite these positive signals, the country was affected by the world economic crisis that is supposed to get worse in 2009, what could complicate even more the situation of poverty that live wide sectors of Guatemalan population. This situation is produced in the midst of unprecedented levels of crime and violence in Guatemala, provoked to a large extent by juvenile gangs and, especially, by organized crime organizations headed by drug trafficking. It is true that such a situation doesn't call to optimism, but neither it is convenient to assume and attitude of defeat, given the country's potentials to recover and continue advancing.
\end{abstract}

Key words: Democracy, crime, poverty, economic stability, political parties. 


\section{TEMAS SOBRESALIENTES DE LA REALIDAD NACIONAL Y SU IMPACTO POLÍTICO}

Esta área se subdivide en cuatro apartados: coyuntura económica, coyuntura social, coyuntura política y coyuntura subregional e internacional.

\section{Coyuntura económica}

A lo largo del año 2008 la actividad económica se vio afectada en forma directa por la desaceleración de la economía mundial, que dio inicio en Estados Unidos y se extendió al resto del mundo. Dentro de esta crítica situación destacaron el incremento de los precios internacionales del petróleo y los alimentos, los cuales incidieron negativamente en el desempeño económico guatemalteco. Es importante destacar que la situación en materia de empleo y producción tampoco mejoró, como lo muestran las mediciones del Índice Mensual de Actividad Económica (IMAE) y las encuestas de la Asociación de Investigación y Estudios Sociales (ASIES). La tasa de crecimiento del PIB fue de 4,3\%, significativamente inferior al 5,6\% registrado en 2007. ${ }^{1}$

El déficit fiscal creció ligeramente respecto al año anterior, ascendiendo al 1,7\% del PIB, lo que ha impedido atenuar las dificultades que enfrenta el fisco. La carga tributaria de 12,1 por ciento el año anterior, se redujo en casi un punto en 2008, alcanzando el 11,2\%. Este porcentaje es inferior al 13\% considerado en los Acuerdos de Paz como el mínimo deseable, el cual no se ha alcanzado desde que dichos acuerdos fueron suscritos hace doce años.

La situación del sistema bancario fue estable, en términos de solvencia y solidez. El otorgamiento de créditos se vio aminorado por la reducción de la liquidez en monedas nacional y extranjera, aunado a la leve alza experimentada en las tasas de interés y las mayores precauciones de las entidades bancarias para otorgar créditos. Aunque la tasa de inflación se mantuvo baja, en niveles positivos en comparación con otras naciones latinoamericanas, tampoco se alcanzó la meta prevista de 5,5\%, ya que giró en torno al 9,4 por ciento. Este indicador positivo no evitó que el crédito al sector privado haya sido menor en un 16,3\% al otorgado el año anterior, lo cual evidencia las dificultades con las que dicho sector se enfrentará a lo largo del año 2009.²

Las proyecciones económicas reflejan que 2009 podría ser aún más crítico, debido a que la crisis alcanzaría su punto más álgido. De verificarse tal tendencia, sería de esperar el inicio de una gradual recuperación a partir de 2010. A pesar de estas dificultades, ocasionadas principalmente por la recesión económica mundial, debe reconocerse que el Gobierno Central ha mantenido indicadores aceptables, gracias a ciertos niveles de austeridad y disciplina en el manejo macroeconómico. Sin embargo, algunos analistas han cuestionado el incremento presupuestario y la baja ejecución del gasto por parte del Ejecutivo. 
A pesar de la desaceleración económica mundial, la crisis no ha impedido algunos logros, especialmente en materia de competitividad, turismo e inversión. En 2008 volvieron a alcanzarse cifras récord en estos sectores, como evidencia de que el nuevo gobierno ha logrado dar cumplimiento a sus políticas. A continuación, algunos indicadores (ver Cuadro 1).

Guatemala ha mejorado su posición en el ranking de competitividad del Foro Económico Mundial donde, pese a encontrarse en una de las posiciones más bajas a nivel latinoamericano, ha sido uno de los países con mejor desempeño en los últimos años. En el índice Doing Business del Banco Mundial, se ha tenido un desempeño positivo en forma constante. ${ }^{3}$

Estos indicadores evidencian que la actual administración gubernamental ha logrado dar cumplimiento a sus políticas de competitividad, turismo y fomento de la inversión, aspectos clave para el desarrollo integral del país. Al mismo tiempo, se hace patente que los logros no han bastado para corregir la aguda inequidad social, la situación de pobreza y exclusión en que vive la población mayoritaria, ni los alarmantes indicadores sociales. Es evidente la falta de mecanismos de redistribución de la riqueza, difíciles de lograr sin la acción conjunta del Estado y la sociedad y en medio de un clima de resistencia al cambio, especialmente en materia fiscal.

\section{Coyuntura social}

La coyuntura social ha seguido dominada por dos problemas fundamentales que se abordarán a continuación: la ola de violencia y criminalidad y los persistentes niveles elevados de pobreza e inequidad.

\section{a. Violencia alarmante}

Los principales problemas que agobian a la población guatemalteca son los elevados niveles de criminalidad y violencia. Guatemala es uno de los países más violentos de América Latina junto con Colombia, México, El Salvador y Honduras. De conformidad

Cuadro 1: Indicadores de competitividad, inversión y turismo

\begin{tabular}{lrrrr}
\hline \multicolumn{1}{c}{ Rubro } & 2005 & 2006 & 2007 & \multicolumn{1}{c}{2008} \\
\hline Ranking de competitividad (posición) & - & 91 & 87 & \multicolumn{1}{c}{84} \\
Índice Doing Business (posición/total países analizados) & \multicolumn{1}{c}{-} & $128 / 155$ & $118 / 175$ & $116 / 178$ \\
Inversión extranjera directa (US\$ millones) & 508,3 & 591,6 & 723,5 & 837,8 \\
Ingreso de turistas (millones) & 1,3 & 1,5 & 1,6 & 1,7 \\
Ingreso de divisas por turismo (US\$ millones) & 868,9 & $1.012,8$ & $1.199,3$ & $1.321,7$ \\
\hline
\end{tabular}

Fuente: elaboración propia sobre la base de SEGEPLAN: I Informe del Presidente al Congreso de la República, 2008. Datos del Ministerio de Gobernación.

3 Gobierno de la República (SEGEPLAN). $1^{\text {er }}$ Año de Gobierno, Primero la Gente. I Informe del Presidente al Congreso de la República 2008. 
con el Observatorio Centroamericano sobre Violencia (OCAVI), Guatemala tiene la segunda tasa de homicidios más alta de América Latina, sólo superada por El Salvador (ver Cuadro 2). ${ }^{4}$

Guatemala es también el país de la región que más pérdidas económicas tiene, en términos absolutos, como consecuencia de la violencia, tal como se observa a continuación (Cuadro 3).

El fenómeno de la violencia obedece principalmente al crimen organizado, en particular el narcotráfico, determinado por la ubicación clave del país como puente entre la producción sudamericana y el mercado estadounidense, dada su frontera directa con América del Norte, región donde está el mayor consumo mundial. En el territorio guatemalteco se ha incrementado la actividad de los poderosos carteles mexicanos, en parte por el éxito

Cuadro 2: Países latinoamericanos con tasas más elevadas de homicidios, 2005-2006 (40/100.000 hab. o más)

\begin{tabular}{|c|c|}
\hline País & Homicidios/100.000 hab. \\
\hline El Salvador & 67,8 \\
\hline Guatemala & 45,2 \\
\hline Colombia & 43,0 \\
\hline Honduras & 42,9 \\
\hline Venezuela & 41,2 \\
\hline \multicolumn{2}{|l|}{ Otros países centroamericanos } \\
\hline Nicaragua & 12,5 \\
\hline Panamá & 11,3 \\
\hline Costa Rica & 7,7 \\
\hline
\end{tabular}

Fuente: elaboración propia, con datos de Acevedo Carlos. Los costos económicos de la violencia en Centroamérica. OCAVI, 2008.

Cuadro 3: Costos económicos de la violencia en Centroamérica

\begin{tabular}{lcr}
\hline \multicolumn{1}{c}{ País } & Millones US\$ & $\%$ PIB \\
\hline Guatemala & $2.291,0$ & 7,7 \\
El Salvador & $2.010,0$ & 10,8 \\
Honduras & 885,2 & 9,6 \\
Nicaragua & 529,0 & 10,0 \\
Costa Rica & 790,8 & 3,6 \\
Total & $6.505,9$ & 7,7 \\
\hline
\end{tabular}

Fuente: elaboración propia, con datos de Acevedo Carlos. Los costos económicos de la violencia en Centroamérica. OCAVI, 2008.

4 Acevedo, Carlos. Los costos económicos de la violencia en Centroamérica. Observatorio Centroamericano sobre Violencia, en www.ocavi.com 
que las autoridades de su propio país han tenido en combatirlos; lo que les ha llevado a trasladarse al vecino del sur. ${ }^{5}$ Entre dichos carteles figuran los de Sinaloa y del Golfo, que han rivalizado entre sí. Estos grupos se han apoderado de extensas áreas del oriente, nororiente y norte del territorio guatemalteco, si bien ya se han expandido también al noroccidente y occidente. Su accionar mina las estructuras del Estado, al constituir un poder paralelo ilegal, con influencias en altas esferas gubernamentales y con aspiraciones de controlar los gobiernos locales en las áreas de su interés.

La violencia también tiene otros orígenes, entre los que destaca el accionar de las pandillas juveniles o maras. En Guatemala existen 111 pandilleros por cada 100.000 habitantes, cifra superada proporcionalmente por El Salvador (180) y Honduras (500). Las pandillas guatemaltecas tienen gran cantidad de integrantes, quizá igual o mayor que las salvadoreñas, en términos absolutos, tomando en cuenta que la población guatemalteca es mayor a la de dicha nación. Si bien el origen de las maras está relacionado con la pobreza, la exclusión social y la falta de oportunidades para la juventud, es sabido que muchas de las pandillas están ligadas a organizaciones del crimen organizado, que las utiliza para llevar a cabo sus acciones. En el cuadro siguiente se observa la incidencia de estos grupos delincuenciales (Cuadro 4).

Es importante destacar otros hechos, como el asesinato de pilotos de autobuses urbanos y extraurbanos. En 2007 las víctimas fueron 167 pilotos, 16 ayudantes y 4 pasajeros. Se teme que este accionar pueda ser, entre otras razones, producto de un plan para desestabilizar al país por determinados grupos criminales con intereses políticos. Destaca el incremento de una práctica asociada principalmente a los pandilleros: las extorsiones. La máxima expresión de este flagelo se da con los pilotos del transporte colectivo, pero también afecta a comercios y personas individuales. ${ }^{6}$

A pesar de los elevados niveles de criminalidad, las autoridades han logrado incrementar su eficacia para combatir de la mejor manera posible este flagelo, pese a los recursos

Cuadro 4: Miembros de pandillas por cada 100.000 habitantes

\begin{tabular}{lc}
\hline País & Pandilleros / (100.000 hab. $)$ \\
\hline Honduras & 500 \\
El Salvador & 180 \\
Guatemala & 111 \\
Nicaragua & 81 \\
Costa Rica & 62 \\
Panamá & 43 \\
\hline
\end{tabular}

Fuente: elaboración propia, con datos de Acevedo Carlos. Los costos económicos de la violencia en Centroamérica. OCAVI, 2008. 
sumamente limitados con que se cuenta. Tal situación puede verse a continuación (ver Cuadro 5).

En medio de la ola de criminalidad, el Gobierno Central ha desplegado esfuerzos para contrarrestar las acciones delincuenciales. Se han impulsado programas sociales, como la generación de empleo, capacitación y recreación para la juventud. Se ha avanzado en la formación de elementos policiales y en la dotación de recursos técnicos y logísticos para la Policía Nacional Civil (PNC) y al Sistema Penitenciario.

Uno de los logros ha sido la implementación de la Comisión Internacional contra la Impunidad en Guatemala (CICIG), aprobada a finales de 2007. Se trata de un ente internacional solicitado por el Estado de Guatemala, apoyado por Naciones Unidas y países cooperantes, para coadyuvar con la investigación criminal y el fortalecimiento del Ministerio Público. También se avanzó en la implementación del Sistema Nacional de Seguridad (SNS), que integra a los entes institucionales del ramo y del Consejo Nacional

Cuadro 5: Cuadro comparativo de incidencia criminal acumulada y acciones positivas registradas.

Período comprendido del 1 de enero al 26 de diciembre, años 2007 y 2008

\begin{tabular}{lcc}
\hline \multicolumn{3}{c}{ Incidencia criminal acumulada } \\
\hline Hechos delictivos & Del 1 ene. al 26 dic. 2007 & Del 1 ene. al 26 dic. 2008 \\
\hline Homicidios & 5.682 & 6.200 \\
Lesionados & 6.160 & 6.870 \\
Delitos contra el patrimonio & 13.470 & 14.576 \\
Delitos sexuales (violaciones) & 315 & 380 \\
Desaparecidos & 1.308 & 1.297 \\
Secuestros & 96 & 182 \\
Violencia intrafamiliar & 2.237 & 2.017 \\
Total & 29.258 & 31.522 \\
\hline
\end{tabular}

\begin{tabular}{lcc}
\hline \multicolumn{3}{c}{ Acciones positivas registradas } \\
\hline Hechos positivos & Del 1 ene. Al 26 dic. 2007 & Del 1 ene. Al 26 dic. 2008 \\
\hline Personas detenidas & 34.891 & 37.007 \\
Vehículos recuperados & 1.411 & 1.780 \\
Motos recuperadas & 273 & 439 \\
Armas de fuego incautadas & 3.693 & 4.522 \\
Indocumentados remitidos & 1.789 & 1.410 \\
Total & 42.057 & 45.158 \\
\hline
\end{tabular}

Fuente: elaboración propia sobre la base de SEGEPLAN: I Informe del Presidente al Congreso de la República, 2008. Datos del Ministerio de Gobernación. 
de Seguridad (CNS), como su instancia coordinadora. El Congreso de la República aprobó la Ley Marco de Seguridad Democrática. ${ }^{7}$

Los avances, aunque modestos, se han logrado pese a que las condiciones para contrarrestar la criminalidad son sumamente precarias. Existen poco menos de 19.000 agentes policiales, uno por cada 755 habitantes cuando el estándar internacional es de uno por cada 300 habitantes; por lo que hacen falta 45.000 agentes para alcanzar el promedio internacional. El sistema penitenciario está colapsado, sin suficiente personal capacitado; sus niveles de saturación son alarmantes, lo cual genera poco control, lo que propicia que en las cárceles se coordinen extorsiones y secuestros. ${ }^{8}$ La falta de coordinación con el sector justicia, plagado de ineficiencia y corrupción, constituye otro factor que coadyuva a que las poderosas redes criminales operen con facilidad. ${ }^{9}$

\section{b. Pobreza y desigualdad que no ceden}

A la problemática en seguridad se suma la que se mantiene en materia social. El fenómeno de la pobreza es dramático. El Índice de Desarrollo Humano (IDH) en 2008 mejoró levemente respecto al año anterior, al pasar de 0,689 a 0,696. En términos reales sigue igual, pues bajó de la posición 118 a la $121 .{ }^{10}$ Guatemala ocupa el penúltimo lugar entre los países de América por su IDH, únicamente por delante de Haití. ${ }^{11}$

El nivel de pobreza general es de $52 \%$ y la pobreza extrema de $15 \%$, mientras que el analfabetismo asciende al 21\%. Según el Banco Mundial, la mortalidad de niños menores de 5 años es de 72 por cada 1.000 nacidos vivos; la desnutrición en personas de dicha edad alcanza al $24 \%$ de los infantes. ${ }^{12}$

En materia de salud se han multiplicado los esfuerzos para ampliar cobertura y mejorar el servicio, en beneficio de la población pobre. En materia educativa pueden observarse a continuación algunos indicadores que evidencian una mejora constante (ver Cuadro 6).

Cuadro 6: Indicadores en educación

\begin{tabular}{cccc}
\hline Año & $\begin{array}{c}\text { Tasa neta de matriculación } \\
\text { educativa, primaria }\end{array}$ & Alfabetización & $\begin{array}{c}\text { Asignación presupuestaria a educación, } \\
\text { ciencia y cultura }(\% \text { del PIB) }\end{array}$ \\
\hline 2005 & 93,5 & 74,8 & 0,0294 \\
2006 & 94,5 & 76,0 & 0,0303 \\
2007 & 95,0 & 77,6 & 0,0292 \\
2008 & 95,3 & 79,0 & 0,0305 \\
\hline
\end{tabular}

Fuente: elaboración propia sobre la base de $1^{\text {er }}$ Año de Gobierno, Primero la Gente, Informe del Presidente al Congreso 2008, datos del Ministerio de Educación.

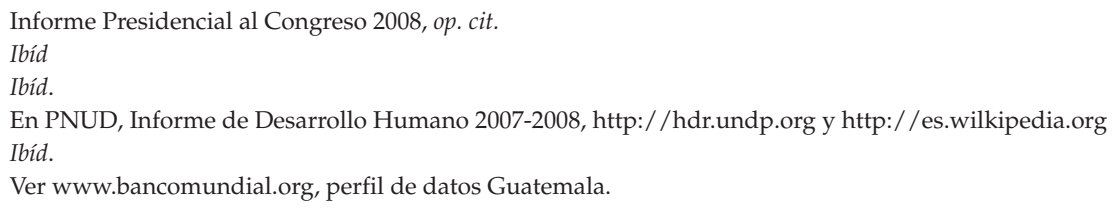


Es evidente la mejora sostenida en materia educativa. En 2008 se alcanzó una cobertura de 95,3\% en el nivel primario, una tasa de alfabetización del 79\% (21\% de analfabetismo) y una asignación presupuestaria del 3,05\% del PIB.

En materia de salud se ha mantenido la tendencia positiva, lográndose avances importantes al alcanzarse cifras récord como la reducción de la mortalidad infantil a 4.263, la materna a 232, incremento de la atención de partos, cirugías y cesáreas, y alcanzándose la suma de 8,9 millones de consultas (ver Cuadro 7).

\section{Coyuntura política}

La coyuntura política ha estado dominada por pugnas entre los distintos grupos que se repartieron cargos públicos, a partir de la llegada de la Unidad Nacional de la Esperanza (UNE) a la Presidencia de la República. Una de ellas la conforman los allegados al mandatario y a su esposa, Sandra Torres de Colom, revestida de múltiples poderes y señalada por sus presumibles aspiraciones presidenciales. Tales sindicaciones han generado la sospecha que sus acciones tienen un trasfondo proselitista de cara a futuros comicios. El Consejo de Cohesión Social, órgano que coordina los principales programas sociales, representa el principal instrumento político del gobierno, lo cual ha conferido a la esposa del mandatario un importante espacio de poder de decisión.

La existencia de un proyecto alternativo en la UNE, encabezado por el diputado Manuel Baldizón, generó un proceso de desmembramiento progresivo, motivado por el interés del líder de este grupo en asumir la Secretaría General del partido, lo que motivó que la dirigencia cercana al Presidente de la República lo sometiera a juicio político por deslealtad a la entidad. Esta pugna provocó la salida de un grupo de diputados, hoy disidentes, que conformaron el Bloque Independiente "Libertad Democrática Renovada" (Líder), quedando en evidencia el proyecto político propio y las aspiraciones presidenciales del diputado Baldizón. ${ }^{13}$

En similar posición se encuentra el diputado Abraham Rivera Sagastume y sus hijos, también congresistas, Abraham y Juan Carlos Rivera Estévez. ${ }^{14}$ Se trata de tres parlamentarios

Cuadro 7: Indicadores en salud

\begin{tabular}{lcccccc}
\hline Año & $\begin{array}{c}\text { Disminución } \\
\text { de mortalidad } \\
\text { infantil }\end{array}$ & $\begin{array}{c}\text { Disminución } \\
\text { de mortalidad } \\
\text { maternal }\end{array}$ & $\begin{array}{c}\text { Atención } \\
\text { de partos }\end{array}$ & Cesáreas & Cirugías & $\begin{array}{c}\text { Consultas } \\
\text { (millones) }\end{array}$ \\
\hline 2007 & 5.255 & 297 & 242.000 & 27.000 & 93.875 & 6,9 \\
2008 & 4.263 & 232 & 293.000 & 32.000 & 120.084 & 8,9 \\
\hline
\end{tabular}

Fuente: elaboración propia sobre la base del $1^{\text {er }}$ Año de Gobierno, Primero la Gente, Informe del Presidente al Congreso 2008, datos del Ministerio de Salud.

13 ASIES: Análisis Socioeconómico y Político Mensual, No 11-12, noviembre-diciembre 2008.

14 Se trata de Amílcar Rivera Estévez, alcalde de Mixco, quien con su padre y sus hermanos Abraham y Juan Carlos conforman el cuarteto de familiares íntimos que impulsan el proyecto político Victoria. 
distritales, disidentes del Partido Patriota (PP), que constituyen una familia con su propio proyecto político, denominado Victoria, que cuenta con apoyo de iglesias neopentecostales. Vale agregar otros cuatro comités pro formación de partido. El primero, denominado Compromiso, Renovación y Orden (CREO), gira en torno al ex funcionario del gobierno de Óscar Berger, Roberto González Díaz-Durán. Los otros son el Comité Podemos, de la ex ministra de Gobernación Adela Camacho de Torrebiarte; el movimiento Winaq, de las dirigentes indígenas Rigoberta Menchú, Premio Nobel de la Paz, y Otilia Lux, ex ministra de Educación, y el Frente de Convergencia Nacional (FCN), encabezado por el coronel José Luis Quilo Ayuso, apoyado por la Asociación de Veteranos Militares de Guatemala (AVEMILGUA). ${ }^{15}$

También ha surgido el Frente Democrático Nacional (FDN), encabezado por el ex presidente Alfonso Portillo, convergencia de tres agrupaciones: el Frente Republicano Guatemalteco (FRG), del controversial ex gobernante Efraín Ríos Montt; la Unión del Cambio Nacionalista (UCN), del ex funcionario portillista Mario Estrada, y un alicaído Partido de Avanzada Nacional (PAN), con afán de resurgimiento bajo el liderazgo del empresario Juan Guillermo Gutiérrez. Portillo busca llegar al Congreso de la República, a efecto de gozar de la inmunidad necesaria ante los tribunales de justicia, que lo persiguen por sus señalamientos de corrupción. Esta nueva coalición tiene fuerte presencia en el interior del país e importante apoyo financiero. ${ }^{16}$

Además del oficialismo y los proyectos políticos nuevos que se perfilan para las elecciones generales de 2011, figuran las principales agrupaciones políticas de oposición. Destacan las opciones de tendencia liberal, inclinadas hacia la derecha del espectro ideológico, como el Partido Patriota del general Otto Pérez Molina, segundo lugar en las últimas votaciones de 2008, y el partido Visión y Valores (VIVA), del pastor evangélico Harold Caballeros, vinculado a iglesias neopentecostales. En la izquierda se mantiene la Unidad Revolucionaria Nacional Guatemalteca (URNG). ${ }^{17}$

\section{Coyuntura regional e internacional}

En el ámbito regional durante 2008 prosiguió el fortalecimiento del Sistema de Integración Centroamericana (SICA). Se avanzó en la Unión Aduanera, encaminada a la conformación de una zona de libre comercio. Los países que más han avanzado son Guatemala y El Salvador, seguidos por Honduras, integrantes del llamado Triángulo Norte.

En la XXII Cumbre de Presidentes se suscribió la Agenda Estratégica Social del SICA que crea un instrumento financiero y un mecanismo de captación de fondos para cumplir sus funciones. También se estableció una Hoja de Ruta Social. Ante la recesión económica que se veía venir, se aprobó el Plan de Medidas Urgentes, que prevé el fortalecimiento de los 
sistemas financieros regionales y el comercio intrarregional, especialmente en materia de seguridad alimentaria e inversión pública en infraestructura. ${ }^{18}$

Se aprobó la implementación del Sistema de Seguridad Turística en Centroamérica y la creación de la Unidad de Operaciones de Mantenimiento de la Paz (UMOP). Se fortaleció la Corte Centroamericana de Justicia, con la incorporación de Guatemala. Se impulsaron la creación del Consejo de Integración Centroamericana, las reformas al Tratado Marco de Seguridad Democrática en Centroamérica y la Estrategia de Seguridad de Centroamérica. Se apoyó el seguimiento de Esquipulas III (Esquipulas de los Pueblos), mecanismo de consulta a las sociedades civiles del istmo, con la finalidad de recoger sus sugerencias relativas al proceso de integración regional. ${ }^{19}$

El proceso de integración regional sigue su curso, a paso lento pero constante. Pese a los avances, persisten numerosos obstáculos a los que se suma el ritmo distinto de cada país, así como cuestionamientos como los planteados al Parlamento Centroamericano (PARLACEN), señalado de ser un organismo costoso, poco funcional y proclive a servir como refugio a políticos corruptos.

En materia de cooperación con socios extrarregionales, una de las principales iniciativas ha sido el Plan Mérida del Gobierno de los Estados Unidos para el combate al narcotráfico en México y Centroamérica, mediante la dotación de fondos adicionales en 2008 y 2009 (en el primer año US\$ 450 millones para México y US\$ 50 millones para Centroamérica y en el segundo US\$ 500 millones para el primero y US\$ 100 millones para la segunda). Esta iniciativa es cuestionada por algunos sectores de opinión, dada su dudosa viabilidad, y al hecho que es considerada como un instrumento para la dominación y penetración de su Ejército en el área. El Plan Mérida ha seguido su implementación en México, pendiente de la aprobación de los fondos para las Centroamérica en 2009. Junto al Plan Colombia, conforman las principales estrategias del gobierno de Estados Unidos de cara al florecimiento del narcotráfico en la región mesoamericana (de México a Colombia). ${ }^{20}$

Otro aspecto de suma importancia en la relación con Estados Unidos es la migración, dado que el gobierno estadounidense ha recrudecido sus medidas contra los migrantes centroamericanos, aumentando su captura y posterior repatriación desde $2007 .{ }^{21}$ A fin de ayudarlos, se impulsan proyectos para trabajadores temporales en Estados Unidos y Canadá. Son claves las acciones políticas que Centroamérica, en forma conjunta y de cada país en particular, realiza ante el Gobierno de Washington, para que las políticas migratorias beneficien a los millones de trabajadores que viven en Estados Unidos.

En relación al mecanismo de cooperación SICA-México, se avanzó en la financiación de la Estrategia de Seguridad Centroamérica-México. Los gobiernos guatemalteco y mexicano continuaron el fortalecimiento del Grupo de Alto Nivel para la Seguridad Fronteriza Guatemala-México (GANSEF). En la X Cumbre del Mecanismo de Diálogo y Concertación

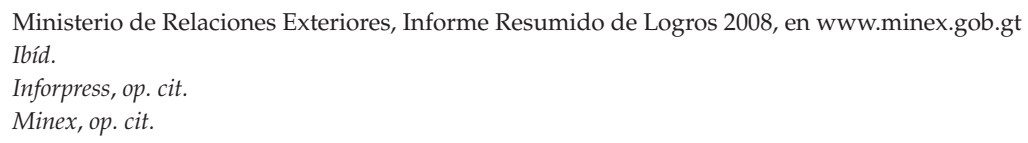


de Tuxtla-Gutiérrez, se reestructuró el Plan Puebla Panamá (PPP), en lo sucesivo Proyecto de Integración y Desarrollo de Mesoamérica, que incluirá a Colombia.22

Avanzaron las negociaciones para la suscripción del Acuerdo de Asociación CentroaméricaUE. Los países europeos cedieron a la demanda centroamericana de negociar a partir del Sistema General de Preferencias (SGP) concedido por la UE hace algunos años, y no como pretendían originalmente. También aceptaron la periodicidad solicitada por los centroamericanos para eliminar los aranceles. Se amplió al 94\% el porcentaje de productos centroamericanos a incursionar sin arancel en el mercado europeo y se ha iniciado la liberalización de barreras arancelarias al banano en los mercados del viejo continente.

A pesar de estos progresos, al final del año se presentan dificultades, como el carácter particularmente sensible de algunos productos centroamericanos que figuran entre el $6 \%$ que no fueron incluidos en los privilegios y el mantenimiento de los polémicos subsidios a los productores agrícolas en Europa. Otro obstáculo es la prioridad que la UE da a otras actividades en el istmo, en detrimento del comercio, así como a otros países y regiones como Sudamérica, y en particular Chile. Cabe añadir que este proceso ha planteado discrepancias entre los gobiernos centroamericanos, particularmente por contrastes ideológicos entre Honduras y Nicaragua (países afines a Hugo Chávez y su área de influencia) y sus vecinos regionales. Estos elementos retardan la negociación del Acuerdo de Asociación, que deja puntos pendientes para 2009. ${ }^{23}$

\section{CAMBIOS SUSTANCIALES EN LAS POLÍTICAS PÚBLICAS}

Uno de los aspectos que han generado expectativas en las políticas públicas es la orientación ideológica socialdemócrata que, desde un inicio, manifestó el equipo gobernante de la UNE, quien hizo ver en su ideario su tendencia menos pro empresarial, que la de administraciones anteriores. Ello no implica una actitud "antiempresa" o de confrontación con el sector privado como la que se produjo en ciertos momentos de la gestión presidencial de Alfonso Portillo (período 1999-2003). En consonancia con su ideología, el nuevo mandatario fijó la prioridad que dará su administración a la política social, para mejorar las condiciones de vida de la población mayoritaria e impulsar mayores niveles de equidad. Se busca poner mayor énfasis en los sectores más pobres y marginales, especialmente en las áreas rurales. ${ }^{24}$

\section{Cohesión social}

En este contexto se enmarcan los programas sociales bajo la coordinación de una nueva instancia creada por Colom: el Consejo de Cohesión Social (CCS), destinado a optimizar la inversión social y evitar duplicidades. Su fin no es ejecutar ni administrar recursos, sino orientarlos hacia las prioridades del país. Su campo de acción abarca los ministerios 
de Salud, Educación, Energía, las secretarías Ejecutiva y de Obras Sociales y los fondos sociales. El CCS seleccionó a los 126 municipios más pobres de los 333 que tiene el país, a cuya población se dota de recursos en tres áreas: infraestructura básica (educación, salud, agua potable y saneamiento, electricidad, accesos viales y vivienda), sostenibilidad (microcréditos y apoyo a proyectos productivos) y programas presidenciales.

El CCS coordina el programa presidencial Mi Familia Progresa, que otorga Transferencias Condicionadas a familias pobres. Se suministra a cada grupo familiar, con hijos en edad escolar, 150 quetzales (aproximadamente US\$20,00), para que sus niños asistan a la escuela. Además, se proporcionan Q150, para que asistan a los establecimientos de salud y nutrición, por lo que una familia puede recibir hasta un máximo de 300 quetzales bimestrales. A lo largo del año, se invirtieron 100,1 millones de quetzales (US\$12,2 millones) en beneficio de 280.000 familias.

En el área urbana se ha implementado la Bolsa Solidaria (bolsa de alimentos otorgada mensualmente a una familia indigente). Se entregaron 62.092 bolsas para beneficiar a 22.250 familias, en 140 asentamientos de la ciudad capital. Se implementaron los Comedores Solidarios, que brindan comida higiénica casi gratuita, lográndose al 31 de diciembre beneficiar a 134.080 personas.

Un tercer programa es el de escuelas abiertas, que promueve en sectores marginales de elevada incidencia delincuencial del área metropolitana actividades de capacitación, culturales, artísticas, deportivas y recreativas para jóvenes en riesgo social, durante los fines de semana, beneficiando en sus primeros meses de existencia (2008) a 56.200 personas. El CCS también lleva a cabo acciones de reconstrucción y remozamiento de aulas y escuelas, reconstrucción en sectores que han sufrido los embates de desastres naturales y dotación de albergues y terrenos para vivienda, por medio del Consejo de Cohesión Social Urbano. ${ }^{25}$

Los programas del CCS han sido cuestionados por dos factores básicos. En primer lugar, por su falta de transparencia, ya que es sumamente difícil fiscalizar las sumas millonarias de recursos públicos que manejan, además que puede dar lugar al clientelismo en favor del partido oficial. La segunda razón de cuestionamiento es que podrían convertirse en una herramienta proselitista para favorecer una eventual campaña electoral de la Primera Dama, Sandra Torres de Colom.

\section{PODER EJECUTIVO}

El Gobierno de la República ha afrontado en 2008 una serie de problemas que han debilitado su gestión y desgastado su imagen pública con rapidez. Entre las debilidades o fisuras que se han evidenciado en el Organismo Ejecutivo figuran las siguientes.

\section{Excesivas pugnas de poder}

Entre las mayores dificultades figuran las pugnas de poder entre diversos grupos que conformaron la maquinaria electoral de la UNE, comunes en cualquier partido ganador 
pero más agudas en este caso, y más rápidas para suscitarse. El problema obedece a que en 2008 asumió el control gubernamental un colectivo político sumamente grande pero con muchas facciones disímiles, algunas difícilmente conciliables; lo que ha planteado al equipo gobernante dificultades desde el inicio.

A la dirigencia de la UNE se suman socialdemócratas de viejo cuño, como Haroldo Rodas, Fernando Fuentes Möhr, Luis Zurita y Óscar Figueroa, entre otros. Igualmente, cuadros de la antigua insurgencia y de organizaciones de la sociedad civil, como Arnoldo Noriega, Pedro Palma Lau, Orlando Blanco y Carlos Barreda, quienes se identificaron con el ideario socialdemócrata y se adhirieron, ocupando hoy importantes cargos públicos. A ellos se han unido algunos empresarios no vinculados a la élite socioeconómica tradicional, pero igualmente pertenecientes al empresariado y con intereses comunes al mismo, quienes figuran en altos puestos después de ser los principales financistas de campaña. Tal es el caso de Carlos Meany, Roberto Dalton y los hermanos y primos Alejos, entre otros.

\section{Improvisación e inconsistencias}

A pesar de contar con numerosos personajes de sectores diversos, analistas independientes consideran que la UNE ha evidenciado una insuficiencia de operadores políticos, capaces de dotar a su administración de la capacidad de interlocución necesaria con los diversos actores sociales. Ha sido igualmente señalada la improvisación que ha imperado en su accionar, la cual es particularmente irónica por parte de un grupo gobernante que, durante el proceso eleccionario, insistió en sus más de ocho años de preparación para gobernar, así como de contar con el mejor programa de gobierno; producto precisamente de esa larga preparación. Su desempeño evidencia que tales aseveraciones, hechas en año electoral, son sumamente cuestionables. ${ }^{26}$

También se ha señalado a la UNE, en sus primeros meses de gobierno, de incumplir con su promesa de campaña de garantizar la estabilidad laboral de los empleados públicos, ofrecida por Álvaro Colom. ${ }^{27}$ De hecho, se les ha sindicado de no corregir la vieja práctica de los gobiernos entrantes, consistente en destituir a numerosos trabajadores de las dependencias estatales para sustituirlos por gente del partido. La nueva administración incurrió en este mal, incluso con más rapidez que las anteriores, afectando sobremanera a algunas instituciones que perdieron cuadros técnicos capacitados y con experiencia.

Otro de los aspectos que se han cuestionado al Organismo Ejecutivo, y en particular al Presidente de la República, son ciertas incongruencias entre el discurso socialdemócrata y la praxis concreta, o algunas lagunas retóricas en que ha incurrido. Se observa tal situación en ejemplos concretos, como cuando el mandatario ha hecho apologías de mártires de la izquierda durante el conflicto armado y ha prometido a organizaciones sociales y humanitarias retomar la memoria histórica para proseguir con la investigación penal; 
pero al mismo tiempo en instalaciones militares ofrece perdón y olvido a los oficiales del Ejército.

De igual forma, cuando el mandatario ha manifestado que logrará cambios trascendentales, no ha precisado con claridad a qué se refiere, a la vez que resulta difícil comprender qué pretende lograr en cuatro años. Otra falencia ha sido su recurrente práctica de culpar a los últimos gobiernos de la problemática imperante, a manera de justificación que, después de un año en el poder, empieza a ser inaceptable. ${ }^{28}$

\section{Excesiva rotación}

Otra de las debilidades que ha manifestado la actual administración en su primer año es la volatilidad en el Gabinete como efecto de la tendencia del mandatario a cambiar funcionarios con más facilidad que sus predecesores, lo cual puede evidenciar pugnas de poder, improvisación, insuficiente capacidad de los cuadros disponibles en el equipo de la UNE, o inestabilidad de quienes conforman la cúpula gubernamental, especialmente del gobernante. ${ }^{29}$ En sólo un año se observaron los siguientes cambios (Cuadro 8):

Como puede observarse, en el transcurso de doce meses el Presidente Colom cambió a cinco ministros de Estado, cerca del 40\% de los titulares de las 13 carteras, dentro de un Gabinete de Gobierno que incluye a secretarios de la Presidencia, comisionados

Cuadro 8: Cambios de ministros en el Gabinete de Álvaro Colom

\begin{tabular}{lll}
\hline \multicolumn{1}{c}{ Ministerio } & \multicolumn{1}{c}{ Funcionario, enero 2008 } & Funcionario, diciembre 2008 \\
\hline Relaciones Exteriores & Haroldo Rodas Melgar & El mismo \\
$\begin{array}{l}\text { Defensa Nacional } \\
\text { Gobernación }\end{array}$ & Marco Tulio García & Abraham Valenzuela González \\
Finanzas Públicas & Vinicio Gómez Ruiz & Francisco Jiménez \\
Economía & Juan Alberto Fuentes Knight & El mismo \\
Agricultura, Ganadería y & Carlos García Macal & Rómulo Caballeros \\
Alimentación & Raúl Robles & Julio Recinos \\
Energía y Minas & Carlos Meany & El mismo \\
$\begin{array}{l}\text { Comunicaciones, Infraestructura } \\
\text { y Vivienda }\end{array}$ & Luis Alejos & El mismo \\
Ambiente y Recursos Naturales & Luis Ferraté Felice & El mismo \\
Educación & Ana Ordóñez de Molina & La misma \\
Cultura y Deportes & Jerónimo Lancerio & El mismo \\
Salud Pública y Asistencia Social & Eusebio del Cid Peralta & Celso Cerezo \\
Trabajo y Previsión Social & Edgar Rodríguez & El mismo \\
\hline
\end{tabular}

Fuente: elaboración propia con datos de Inforpress, N 1735,11 de enero de 2008, p. 3.

28 Ibid.

29 Inforpress, op. cit., 1735 y Prensa Libre, 17 de marzo de 2009, en www.prensalibre.com 
presidenciales y otros altos funcionarios. Obviando el caso del Ministerio de Gobernación, donde el relevo fue producto de la muerte trágica del titular en un accidente aéreo, los otros cuatro funcionarios fueron reemplazados en las carteras de Defensa, Economía, Agricultura y Salud. Al margen de que alguno de los sustituidos renunciara aduciendo motivos personales o quebrantos físicos, en general se coincide en que los cuatro ministros dejaron el cargo a instancias del Presidente de la República o su esposa.

Vale agregar que en tres casos, Gobernación, Agricultura y Economía, los "segundos" ministros también fueron relevados en las primeras semanas de 2009, de tal suerte de que en menos de 15 meses dichos ministerios han tenido tres titulares cada uno. ${ }^{30}$ Asimismo, en un año ha habido cambios en varias secretarías presidenciales, como las de Planificación, Obras Sociales, Bienestar Social, Ejecutiva, de Asuntos Administrativos y de Seguridad, etc. No menos significativos han sido los relevos de numerosos viceministros y subsecretarios, así como de los titulares de dependencias más específicas como las direcciones de la Policía Nacional Civil (PNC), el Sistema Penitenciario y otras más. ${ }^{31}$

Si bien el Presidente Colom ha sido claro en que está en la disposición de reemplazar a cuanto funcionario sea las veces que sea necesario, en aras de un óptimo desempeño, un eventual exceso de reemplazos puede implicar riesgos. Concretamente, puede suscitarse cierta inestabilidad dentro del Gabinete y del Ejecutivo mismo. También puede darse la propensión a tener una administración más errática en el manejo de la cosa pública, que si los cambios fuesen más selectivos y esporádicos. Tales riesgos son particularmente evidentes, tomando en cuenta que si se mantienen los relevos en la misma proporción en los tres años siguientes, la cantidad de reemplazos podría ser desmedida.

\section{PODER LEGISLATIVO}

El Congreso de la República, a lo largo de 2008, se ha visto agobiado por algunos actos de corrupción, y especialmente por la volatilidad de los grupos parlamentarios y la escasa producción de leyes. Destaca el desfalco de 82,8 millones de quetzales (cerca de US\$ 10 millones) que se depositaron en una financiera privada, los cuales desaparecieron junto con dos funcionarios del Legislativo implicados en el caso, hoy prófugos de la justicia. Tal situación motivó la renuncia del Presidente del Congreso, el diputado oficialista Eduardo Meyer, y la pérdida de su inmunidad para que enfrente a los Tribunales de Justicia. También se han producido serios señalamientos a su antecesor, el ex presidente del Legislativo y aún diputado Rubén Darío Morales, quien se rehúsa a enfrentar a la justicia mediante una serie de subterfugios, y en cuyo período se llevaron a cabo otras transacciones anómalas similares. ${ }^{32}$

30 En marzo de 2009 Rómulo Caballeros, sustituto de Carlos García Macal, fue a su vez sustituido como titular de Economía por su viceministro, Rubén Morales Monroy. En agricultura Julio Recinos, que había reemplazado a Raúl Robles, fue a su vez relevado por Mario Aldana Pérez. En gobernación, el nuevo ministro es Salvador Gándara (tras dejar la secretaría ejecutiva), en lugar de Francisco Jiménez, quien a su vez había llegado en reemplazo de Vinicio Gómez.

$31 \quad$ Ibíd.

32 Prensa Libre, 23 de diciembre de 2008, en www.prensalibre.com 
Como consecuencia positiva de este hecho, en lo sucesivo los fondos del Organismo Legislativo se depositarán en el Banco de Guatemala. Otro efecto favorable es la separación de las funciones políticas y las administrativas, quedando estas últimas desligadas de los diputados y a cargo de personal específico. Sin embargo, se trata de avances logrados de manera irregular, como consecuencia de hechos lamentables que les antecedieron y no de un genuino desarrollo institucional. Otro logro positivo en el Legislativo fue la aprobación de algunas normativas de suma importancia para el país. ${ }^{33}$

\section{Permanentes pugnas y divisiones}

Una de las características que ha dominado al Congreso de la República es la relativa volatilidad de las bancadas principales, las cuales se han dividido por las intensas pugnas de poder imperantes. Esta situación, suscitada en relativamente poco tiempo, evidencia que aún persisten elevados niveles de clientelismo político, deslealtad y "transfuguismo" en la clase política guatemalteca, como evidencias de la insuficiente madurez y el exceso de intereses personales que aún priman entre muchos de sus integrantes. ${ }^{34}$ Las deserciones, que han desembocado en el surgimiento de dos nuevas bancadas y de un grupo de diputados independientes, han afectado especialmente a agrupaciones mayoritarias, si bien proporcionalmente algunas fracciones menores también se han visto afectadas por la pérdida de diputaciones (ver Cuadro 9).

El partido oficial Unidad Nacional de la Esperanza (UNE) no obtuvo mayoría absoluta en las elecciones legislativas de 2007, pero los 51 escaños ganados son suficientes para constituir el grupo parlamentario más grande. Esta bancada duró unida pocos meses, ya que durante 2008 se separaron 11 diputados de su bancada original (equivalentes al 21,6\%) que pasaron a integrar la bancada Líder, encabezada por el diputado Manuel Baldizón, quienes pasaron del oficialismo a la abierta oposición al gobierno (ver coyuntura política).

En lo que respecta a la otrora oficialista Gran Alianza Nacional (GANA), que en los últimos comicios logró la segunda bancada más grande, ésta se dividió en dos fracciones cuando algunos funcionarios de la anterior administración del ex presidente Óscar Berger (2004-2008) perdieron el control del partido. Como consecuencia de las luchas de poder, especialmente por la presidencia de comisiones de trabajo, 14 parlamentarios se retiraron de la bancada original, lo que supuso la pérdida de más de un tercio de sus 37 escaños iniciales $(37,8 \%) .{ }^{35}$ Estos disidentes, con excepción de dos que se constituyeron en independientes, conformaron la Bancada Guatemala (BG). A este nuevo grupo parlamentario se sumaron el diputado Abraham Rivera Sagastume y sus hijos Abraham y Carlos (ver coyuntura política). Con ellos, la BG suma 15 escaños, constituyendo una de las principales fuerzas en el Congreso de la República.

A las bancadas Guatemala y Líder, conformadas por 26 parlamentarios, se suman 8 diputados independientes que incluyen a dos disidentes de la GANA mencionados con anterioridad. Vale agregar a 3 congresistas de Encuentro por Guatemala (EG), fuerza 
Cuadro 9: Guatemala: conformación del Congreso de la República, 2007-2008

\begin{tabular}{|c|c|c|c|c|c|c|c|c|}
\hline \multirow[b]{2}{*}{ Agrupación } & \multicolumn{4}{|c|}{ Escaños, Elecciones 2007} & \multicolumn{4}{|c|}{ Escaños, cambios en 2008} \\
\hline & $\begin{array}{c}\text { Lista } \\
\text { Nacional }\end{array}$ & Distritales & Total & $\%$ & $\begin{array}{c}\text { Lista } \\
\text { Nacional }\end{array}$ & Distritales & Total & $\%$ \\
\hline \multicolumn{9}{|c|}{ Grupos Parlamentarios Originales } \\
\hline UNE & 8 & 43 & 51 & 32.3 & 7 & 33 & 40 & 25.3 \\
\hline GANA & 6 & 31 & 37 & 23.4 & 2 & 22 & 24 & 15.2 \\
\hline PP & 6 & 23 & 29 & 18.4 & 6 & 19 & 25 & 15.8 \\
\hline FRG & 3 & 11 & 14 & 8.8 & 3 & 11 & 14 & 8.9 \\
\hline PU & 2 & 5 & 7 & 4.4 & 2 & 5 & 7 & 4.4 \\
\hline CASA & 1 & 4 & 5 & 3.2 & 1 & 2 & 3 & 1.9 \\
\hline UCN & 1 & 4 & 5 & 3.2 & 1 & 4 & 5 & 3.3 \\
\hline EG & 2 & 2 & 4 & 2.5 & 1 & - & 1 & 0.6 \\
\hline PAN & 1 & 2 & 3 & 1.9 & - & 2 & 2 & 1.2 \\
\hline URNG-MAIZ & 1 & 1 & 2 & 1.3 & 1 & 1 & 2 & 1.2 \\
\hline UD & - & 1 & 1 & 0.6 & - & 1 & 1 & 0.6 \\
\hline \multicolumn{9}{|c|}{ Nuevos grupos parlamentarios } \\
\hline BG & - & - & - & - & 4 & 11 & 15 & 9.5 \\
\hline Líder & - & - & - & - & 1 & 10 & 11 & 7.0 \\
\hline Independientes & - & $-w w$ & - & - & 2 & 6 & 8 & 5.1 \\
\hline Total & 31 & 127 & 158 & 100.0 & 31 & 127 & 158 & 100.0 \\
\hline
\end{tabular}

Fuente: elaboración propia con datos del Congreso de la República, www.congreso.gob.gt

minoritaria que a la larga ha sido la más afectada por el transfuguismo, al perder al $75 \%$ de sus 4 diputados originales y quedar únicamente con su líder y fundadora, Nineth Montenegro. Otra bancada menor, también afectada por dicho fenómeno, ha sido la del Centro de Acción Social (CASA), que perdió dos legisladores, de los cuales uno se declaró independiente y el restante se unió a la GANA, que con ello subió de 23 a 24 escaños. $^{36}$

Contrasta con las anteriores la estabilidad de la tercera agrupación más numerosa dentro del Congreso original, que ya ha pasado a ser la segunda: el Partido Patriota (PP). Este grupo parlamentario solamente ha perdido a 4 de sus 29 legisladores originales, siendo éstos los tres congresistas de la familia Rivera, antes mencionados, y el diputado Aníbal Augusto Salguero, separado del partido por tener un juicio pendiente. Similar disciplina a la que caracteriza a la bancada Patriota ha mantenido la que, a cierta distancia de las anteriores, constituye la cuarta fuerza en el hemiciclo y que mantiene aún cierto peso: el Frente Republicano Guatemalteco (FRG). Esta agrupación, en el poder durante el período 
presidencial de Alfonso Portillo y encabezada por el controversial ex jefe de gobierno, general Efraín Ríos Montt, ha mantenido incólume su compacta pero nada desdeñable bancada de 14 diputados.

Igual inamovilidad ha caracterizado a los 7 congresistas del Partido Unionista, del ex Presidente de la República y actual alcalde de la Ciudad de Guatemala, Álvaro Arzú, y a los 5 de la Unión del Cambio Nacionalista (UCN), encabezados por el ex diputado Mario Estrada, ex funcionario y actualmente aliado político de Portillo. Esta estabilidad demuestra la solidez que puede caracterizar a algunos bloques parlamentarios menores, cuya relativa pequeñez no impide que sean estables, con base en la disciplina partidaria y la lealtad de la que han carecido otros, como EG y CASA. ${ }^{37}$

\section{Pobre producción de leyes}

Destaca la pobre generación de leyes, si bien algunas aprobadas fueron de suma importancia. La relación de las leyes aprobadas y las que quedaron pendientes se evidencia en el cuadro siguiente (Cuadro 10).

El Congreso de la República aprobó leyes en materia de auditoría social, transparencia y fortalecimiento de la democracia y del sistema judicial, derechos humanos e igualdad social, así como en el campo de la salud. Están aún pendientes otras normativas en áreas como desarrollo rural, sistema político, administración pública y, especialmente, en un campo crucial para el país en la actualidad como lo es la seguridad. ${ }^{38}$

\section{RELACIÓN ENTRE LOS PODERES DEL ESTADO}

Una de las características que ha predominado en las relaciones entre los poderes del Estado es la tensión, muy usual en esta interacción, en particular entre el Ejecutivo y el

Cuadro 10: Principales normativas aprobadas y pendientes

\begin{tabular}{ll}
\hline \multicolumn{1}{c}{ Leyes aprobadas en 2008 } & \multicolumn{1}{c}{ Leyes pendientes } \\
\hline Ley de Acceso a la Información Pública & Ley de Armas y Municiones \\
Ley contra el Femicidio & Ley de Agencias Privadas de Seguridad \\
Ley Marco del Sistema Nacional de & Ley de Desarrollo Rural \\
Seguridad & Ley de Servicio Civil \\
Ley de Extradiciones & Reformas a la Ley Electoral y de Partidos \\
Reformas a la Ley de la Carrera Judicial & Políticos \\
Ley de Espacios Libres de Humo de Tabaco & \\
\hline
\end{tabular}

Fuente: elaboración propia, sobre la base de Prensa Libre, 23 diciembre 2008. www.prensalibre.com

38 Prensa Libre, 23 de diciembre de 2008, op. cit. 
Legislativo. Cada caso reviste sus peculiaridades, y la evolución más o menos favorable dependerá de la habilidad de las autoridades de turno para manejar la situación. En lo que respecta al año 2008, tales relaciones estuvieron dominadas por el divisionismo, el cual se dio desde un inicio en el partido oficial, motivado principalmente por la pugna entre el grupo afín al mandatario y el del diputado Baldizón, antes mencionado.

A manera de compensación para el oficialismo, cuya bancada se dividió en dos, la división al interior de la GANA debilitó a las dos fracciones del partido original y favoreció la capacidad del debilitado bloque oficialista para hacer alianzas coyunturales con otras bancadas. No obstante, el apoyo que en determinados momentos ha recibido de las dos fracciones de la antigua GANA, del FRG y de otras agrupaciones, el oficialismo ha debido enfrentarse a un bloque opositor. Este es encabezado por el PP, que constituye la mayor fuerza de oposición y que actualmente mantiene coincidencias con la bancada Líder de Baldizón y con otros grupos parlamentarios menores. ${ }^{39}$

La interacción Gobierno-Congreso ha tenido altibajos, por lo que ha habido momentos de distensión que favorecen al partido gobernante, pues incrementan la posibilidad de que los legisladores cedan a sus iniciativas. Incluso, llegó a haber a inicios del período presidencial una alianza coyuntural entre las bancadas mayoritarias (UNE, GANA y Patriota), que permitió al Ejecutivo lograr la aprobación de cinco préstamos para financiar el Presupuesto nacional. Poco tiempo después se rompió dicha coalición y las bancadas opuestas a la UNE, encabezadas por el bloque Patriota y más tarde Líder, volvieron a su política de oposición en un contexto de crecientes tensiones, especialmente entre los dos partidos más grandes del país (UNE y Patriota). Esta situación ha requerido cierta habilidad de la UNE para manejar su relación con otras bancadas, permitiéndole salir airosa en sus principales iniciativas.

La situación se ha complicado por momentos, como cuando el presidente Álvaro Colom hizo ver a los diputados, incluidos los de su partido, que habría una separación tajante entre ambos organismos del Estado, por lo que los congresistas no tendrían la menor opción a proponer nombramientos de personal para laborar en el Estado y quedarían al margen del listado geográfico de obras. La decisión presidencial, aparentemente apegada al principio de separación de poderes, podría resultar poco realista ante las cuotas de poder que se reparten los partidos políticos tras una elección, además que coadyuvaría a debilitar la influencia del Presidente entre los parlamentarios, en su propio detrimento.

En todo caso, el debilitamiento del oficialismo ha sido inevitable, al extremo que incluso se ha hablado sobre el intercambio de prebendas suscitado entre los organismos Ejecutivo y Legislativo, como única vía para poder gobernar. Lo preocupante de este fenómeno, es la posibilidad de que el Presidente Colom pudiese retornar a prácticas análogas a las del ex Presidente Jorge Serrano (1991-93), cuya relación con el Congreso degeneró en un juego de chantajes y sobornos que causaron su salida de la Presidencia. Los poderes del Estado y los partidos políticos, especialmente los dos mayoritarios, deberán apelar a la cordura 
para mantener el mínimo de estabilidad en sus relaciones, básica para el mantenimiento de la institucionalidad.

\section{PERCEPCIONES CIUDADANAS}

Un aspecto final a ser abordado brevemente es la percepción de la ciudadanía respecto al desempeño de Guatemala en materia de democracia y estado de derecho. Es importante destacar que se ha mejorado constantemente en el Índice de Percepción de la Corrupción de Transparency International (que oscila entre 0, que es el más corrupto y 10, el más limpio del mundo). Si bien la nación guatemalteca se encuentra aún por debajo de la media mundial, entre 2004 y 2008 pasó de 2,4 a un 3,1 que le ubica como un país que ha mejorado significativamente la percepción sobre honradez, y que incluso ha dejado de ser el peor de Centroamérica, superando a Honduras y a Nicaragua. ${ }^{40}$

De igual forma, en materia de libertades, según Freedom House, donde el nivel óptimo es 1 y el pésimo es 7, Guatemala ha pasado de 4 a 3 en derechos políticos y se mantiene en 4 en materia de libertades civiles. Tales indicadores la convierten en un país parcialmente libre, por debajo de los totalmente libres pero mucho mejor que los no libres, que son numerosos países. En este aspecto, la situación se ha mantenido relativamente estática. ${ }^{41}$

Por último, se tienen los indicadores de Latinobarómetro 2008, elaborado en Chile, según los cuales Guatemala es el segundo país latinoamericano que ve con mayor pesimismo el horizonte para el próximo año, con un nivel de $45 \%$ de visión optimista sólo superior al 44 por ciento del Perú, frente al 83\% de Paraguay (quizá porque acababa de elegir Presidente), y un promedio latinoamericano de 55\%. En el nivel de aprobación del Gobierno también estaba entre los más bajos, con $46 \%$ frente al $86 \%$ del más alto y $14 \%$ del más bajo (una vez más Paraguay y Perú, respectivamente) y el 52\% regional. De igual forma, la confianza en el Gobierno era del $84 \%$ y el $15 \%$ en los extremos (siempre paraguayo y peruano), $44 \%$ el latinoamericano y $28 \%$ en el caso guatemalteco, de nuevo entre los más bajos. ${ }^{42}$

\section{EVALUACIÓN GENERAL SOBRE EL FUNCIONAMIENTO Y LA CALIDAD DE LA DEMOCRACIA}

La realidad observada en relación al comportamiento de la democracia durante 2008 evidencia una situación ambivalente que da lugar al escepticismo, o a un optimismo cauteloso. Es evidente que ha habido avances, como el mantenimiento de la institucionalidad civil, la alternabilidad en el poder y la repartición relativamente equitativa del mismo entre una pluralidad de opciones que se hacen contrapeso entre sí. Esta situación evidencia que el régimen democrático, vigente desde 1986, busca su consolidación bajo el liderazgo de autoridades popularmente electas. 
De igual forma, puede considerarse como positivo el hecho de que, por primera vez en muchos años, hace gobierno una organización de tendencia socialdemócrata que, más allá de sus posibles inconsistencias, intenta reducir en alguna medida la hegemonía de agrupaciones de tendencia más liberal o conservadora, ubicadas más hacia la derecha del espectro político-ideológico y afines al empresariado tradicional. Este hecho puede considerarse favorable, en un país donde la izquierda como contrapeso ha permanecido sumamente débil, pese a que no hay una política de Estado diseñada para reprimirla o coartarla.

Otro aspecto providencial es la consolidación de un régimen donde prácticamente se da por descartado el recurso al autoritarismo y los golpes de Estado, donde el grupo gobernante ha mantenido cierta actitud abierta al diálogo y a la búsqueda de consensos. También se puede considerar positiva la prioridad que se ha dado a las políticas sociales y su orientación hacia el interior de la República, con énfasis en los municipios especialmente en los más pobres del país.

Los aspectos positivos antes mencionados no deben dar lugar al exceso de optimismo, ya que la realidad del país también tiene problemas notables. En primer lugar, la polarización y las propensiones a la confrontación entre los actores sociales aún no se han superado, de tal suerte que se suele carecer de la madurez y la tolerancia necesarias para viabilizar procesos, dada la tendencia a la imposición que sigue privando entre ciertos sectores. En este contexto, se enmarca la intolerancia a la crítica que ha manifestado en determinados momentos el grupo político gobernante, cuya actitud no deja de ser ambivalente, ya que al mismo tiempo da muestras de apertura hacia ciertos sectores.

A esta atomización se suma el problema más grave que enfrenta el país: el elevado nivel de violencia e impunidad que aún prevalece. Sobresale el auge que siguen manteniendo las organizaciones del crimen organizado, encabezadas por las organizaciones del narcotráfico, que están copando zonas enteras del territorio y coadyuvando a la impunidad y debilitamiento del régimen de derecho en forma constante. Vale agregar el accionar de las pandillas juveniles o maras, como otro problema que azota a la juventud y a la sociedad, igualmente generador de violencia e inestabilidad.

No menos importantes son los elevados niveles de pobreza e inequidad social, en una nación que aún no ha logrado superar los agudos grados de concentración y exclusión que le caracterizan, pese a los innegables avances alcanzados en los diversos campos de la política social, significativos pero insuficientes. El hecho de que a pesar de los progresos alcanzados en materia de exportaciones, inversiones, turismo, etc., el país siga estando entre los que tienen los peores indicadores sociales es evidencia inequívoca de que deben redoblarse los esfuerzos en este campo, con la conciencia de que el crecimiento económico por sí mismo no basta si no se busca una distribución más equitativa de la riqueza. Este esfuerzo requiere el involucramiento de los sectores productivos del país.

Vale agregar un elemento valioso como lo ha sido la cooperación técnica y financiera a Guatemala por parte de pueblos amigos, de gran ayuda para el país. Pero este aspecto tan 
positivo también tiene su contraparte, como es la excesiva vulnerabilidad que caracteriza a esta pequeña nación, y a sus vecinas centroamericanas, en relación a los vaivenes de la situación internacional. Esta realidad se ha hecho patente en este momento, en que Centroamérica prosigue en sus esfuerzos integracionistas, pero al mismo tiempo sufre los efectos de la crisis económica mundial.

Puede concluirse que la democracia guatemalteca se mantiene, pero adolece de debilidades que amenazan su consolidación. Ante el panorama complejo que se presentó en 2008, derivado de la problemática global, los errores gubernamentales y los divisionismos sociales y la criminalidad, y dadas las perspectivas económicas pesimistas para el 2009, el reto político esencial consiste en consolidar la endeble democracia guatemalteca y evitar que retroceda o se desmorone.

\section{REFERENCIAS}

Acevedo, Carlos. 2008. Los costos económicos de la violencia en Centroamérica. Observatorio Centroamericano sobre Violencia (OCAVI). [En línea] <www.ocavi.com>.

Asociación de Investigación y Estudios Sociales (ASIES). 2008. “Análisis Socioeconómico y Político Mensual". Departamento de Investigaciones Sociopolíticas (DISOP). Publicaciones. [En línea] $<$ http://www.asies.org.gt/PUBLICACIONES.HTM>. Números 1 (enero) y 11-12 (noviembrediciembre).

Asociación de Investigación y Estudios Sociales (ASIES). 2008. “Desarrollo económico y social de Guatemala en 2008". En Evaluación Macroeconómica y Social de Guatemala durante el primer semestre de 2008. Revista ASIES No. 4, 2008, 2 a parte. Guatemala: ASIES, Pp. 45-90.

Asociación de Investigación y Estudios Sociales, enero de 2009. Evaluación Anual de la Actividad Económica y Perspectivas para 2009. Guatemala: ASIES.

Asociación de Investigación y Estudios Sociales (ASIES). 2008. Guatemala: Monografía de los partidos políticos 2004-2008. Revista ASIES N ${ }^{\circ}$ 4, 2008, $2^{\text {a }}$ parte. Guatemala: Departamento de Investigaciones Sociopolíticas (DISOP), ASIES.

Asociación de Investigación y Estudios Sociales (ASIES). 2008. Política Económica 2004-2008. Revista ASIES N ${ }^{\circ} 4,2008,2^{a}$ parte. Guatemala: Departamento de Investigaciones y Consultoría Económica, ASIES.

Banco Mundial. Perfil de datos Guatemala [en lìnea] <www.bancomundial.org>

Corporación Latinobarómetro. Informe 2008. Santiago de Chile. (En línea). En www.latinobarometro. org

El Periódico, 1 de marzo de 2009, Portillo vuelve a las tarimas y llama a integrar frente democrático. [En línea] <www.elperiodico.com.gt $>$.

Freedomhouse. Freedom in the World 2008. [En llínea] <http:// www.freedomhouse.org>.

Gobierno de Guatemala (Secretaría de Planificación y Programación de la Presidencia, SEGEPLAN), 2008. 1er Año de Gobierno: Primero la Gente. Informe del Presidente al Congreso de la República. Guatemala: SEGEPLAN.

Ministerio de Relaciones Exteriores, Informe Resumido de Logros 2008, [en línea]<www.minex.gob.gt>. Inforpress Centroamericana, 2008 (1734-1781). Números 1735-37; 1753-54; 1759; 1761-62; 1774; 1776; 1781.

Prensa Libre. "Cambios en gabinete de Älvaro Colom", 17 de marzo de 2009. Guatemala.

Prensa Libre. "Congreso sin credibilidad ni resultados de impacto", 23 de diciembre de 2008. Guatemala.

Prensa Libre. "Sospechan conspiración en asesinatos de pilotos", 6 de marzo de 2009. Guatemala.

Programa de Naciones Unidas para el Desarrollo (PNUD). Informe de Desarrollo Humano 2007-2008.

[En línea] <http//:www.hdr.undp.org> 
Solís, Fernando. 2008. "El gobierno de Álvaro Colom y la Unidad Nacional de la Esperanza: una lectura política", en El Observador. Año 3, Nos 11 y 12, Pp. 3-24.

Transparency International (Transparencia Internacional). Índice de Percepción de la Corrupción. [En línea] <http:// www.transparency.org >.

Renzo Lautaro Rosal. Politólogo con especialización en Sociología Política. Tiene una Maestría en Relaciones Internacionales (FLACSO/Universidad Rafael Landívar). Actualmente Director de la Maestría en Desarrollo de la Universidad del Valle y Director Adjunto del Instituto Centroamericano de Estudios Políticos (INCEP). Columnista en el periódico Prensa Libre. Investigador y consultor de procesos electorales y políticas públicas. Analista político. Consultor internacional en descentralización y fortalecimiento de gobiernos locales. Funcionario público en varias administraciones de gobierno, habiendo sido Subsecretario Ejecutivo de la Presidencia, responsable del proceso de descentralización.

[E-mail: rlrosal@yahoo.es]

Hugo Antonio Solares. Politólogo con especialización en Sociología Política. Tiene una Maestría en Relaciones Internacionales (FLACSO/Universidad Rafael Landívar) y una Maestría en Desarrollo de la Universidad del Valle de Guatemala. Actualmente es Analista Político del Instituto Centroamericano de Estudios Políticos (INCEP). Ha sido investigador sociopolítico, analista político, consultor en políticas públicas y docente universitario en instituciones como la Secretaría de Planificación de la Presidencia, la Facultad Latinoamericana de Ciencias Sociales y la Fundación Soros Guatemala, entre otras. Sus áreas de especialización son políticas públicas, seguridad ciudadana, descentralización y poder local y relaciones internacionales.

[E-mail hasolares@gmail.com] 
